\title{
Distribution of espM and espT among enteropathogenic and enterohaemorrhagic Escherichia coli
}

\author{
Ana Arbeloa, ${ }^{1} \dagger$ Miguel Blanco, ${ }^{2} \dagger$ Fabiana C. Moreira, ${ }^{3}$ Richard Bulgin, ${ }^{1}$ \\ Cecilia López, ${ }^{2}$ Ghizlane Dahbi, ${ }^{2}$ Jesús E. Blanco, ${ }^{2}$ Azucena Mora, ${ }^{2}$ \\ María Pilar Alonso, ${ }^{4}$ Rosalia Ceferina Mamani, ${ }^{2}$ Tânia A. T. Gomes, ${ }^{3}$ \\ Jorge Blanco ${ }^{2}$ and Gad Frankel ${ }^{1}$ \\ ${ }^{1}$ Centre for Molecular Microbiology and Infection, Division of Cell and Molecular Biology, Imperial \\ College London, London SW7 2AZ, UK \\ ${ }^{2}$ Laboratorio de Referencia de E. coli, Departamento de Microbiología y Parasitología, Facultad de \\ Veterinaria, Universidad de Santiago de Compostela, Lugo, Spain \\ ${ }^{3}$ Departamento de Microbiologia, Imunologia e Parasitologia, Universidade Federal de São Paulo, \\ São Paulo, Brazil \\ ${ }^{4}$ Unidade de Microbioloxía Clínica, Complexo Hospitalario Xeral-Calde, Lugo, Spain
}

Correspondence
Jorge Blanco
jorge.blanco@usc.es
Gad Frankel
g.frankel@imperial.ac.uk

Received 12 February 2009

Accepted 7 April 2009

\begin{abstract}
Enterohaemorrhagic Escherichia coli (EHEC) and enteropathogenic E. coli (EPEC) translocate dozens of type III secretion system effectors, including the WxxxE effectors Map, EspM and EspT that activate Rho GTPases. While map, which is carried on the LEE pathogenicity island, is absolutely conserved among EPEC and EHEC strains, the prevalence of espM and espT is not known. Here we report the results of a large screen aimed at determining the prevalence of espM and espT among clinical EPEC and EHEC isolates. The results suggest that espM, detected in $51 \%$ of the tested strains, is more commonly found in EPEC and EHEC serogroups that are linked to severe human infections. In contrast, espT was absent from all the EHEC isolates and was found in only $1.8 \%$ of the tested EPEC strains. Further characterization of the virulence gene repertoire of the espT-positive strains led to the identification of a new $\zeta 2$ intimin variant. All the espT-positive strains but two contained the tcc $P$ gene. esp $T$ was first found in Citrobacter rodentium and later in silico in EPEC E110019, which is of particular interest as this strain was responsible for a particularly severe diarrhoeal outbreak in Finland in 1987 that affected 650 individuals in a school complex and an additional 137 associated household members. Comparing the protein sequences of EspT to that of E1 10019 showed a high level of conservation, with only three strains encoding EspT that differed in 6 amino acids. At present, it is not clear why espT is so rare, and what impact EspM and EspT have on EPEC and EHEC infection.
\end{abstract}

\section{INTRODUCTION}

Enterohaemorrhagic Escherichia coli (EHEC) comprise a subgroup of Shiga-toxin producing E. coli that can cause bloody diarrhoea, haemorrhagic colitis and haemolyticuraemic syndrome (reviewed by Tarr, 1995). EHEC

†These authors contributed equally to this work.

Abbreviations: A/E, attaching and effacing; aEPEC, atypical enteropathogenic Escherichia coli; EHEC, enterohaemorrhagic Escherichia coli; EPEC, enteropathogenic Escherichia coli; SF, sorbitol fermenting; tEPEC, typical enteropathogenic Escherichia coli.

The GenBank/EMBL/DDBJ accession numbers for the eae- $\zeta 2$ variant gene sequences of E110019 and T2381-8 are FM872419 and FM872420, respectively.
O157:H7 is the most common and virulent serotype that is implicated worldwide in human disease, although nonO157 EHEC serotypes, particularly O26, O103, O111, O118 and O145, are also prevalent (reviewed by Nataro \& Kaper, 1998). Enteropathogenic E. coli (EPEC) is the leading cause of mortality due to infantile diarrhoea in the developing world (reviewed by Chen \& Frankel, 2005). EPEC strains comprise a diverse group of serotypes that may be divided into typical EPEC (tEPEC) and atypical EPEC ( $\mathrm{aEPEC}$ ) based on the presence or absence of a large virulence plasmid (EAF), respectively (Kaper, 1996)

EPEC and EHEC, as well as the mouse pathogen Citrobacter rodentium (reviewed by Mundy et al., 2005), colonize the gut mucosa via attaching and effacing $(\mathrm{A} / \mathrm{E})$ 
lesions, which are characterized by the close association of the bacteria with the enterocyte plasma membrane and localized breakdown of the brush border microvilli (Knutton et al., 1987; reviewed by Frankel \& Phillips, 2008). The ability to induce $\mathrm{A} / \mathrm{E}$ lesions is associated with the LEE pathogenicity island, which encodes gene regulators, intimin (Jerse et al., 1990), a type III secretion system (Jarvis et al., 1995), chaperones, translocator and effector proteins (reviewed by Garmendia et al., 2005a). The principal effector protein needed for A/E lesion formation is Tir, which, once translocated, is integrated into the mammalian cell plasma membrane where it serves as a receptor for intimin (Kenny et al., 1997). Recent studies have shown that different EPEC and EHEC strains encode distinct intimin and Tir types; currently there have been 27 intimin and 8 Tir types reported (Blanco et al., 2006a, b; Garrido et al., 2006; J. Blanco, unpublished data).

EPEC E2348/69, which is the prototype strain used worldwide to study EPEC infection, encodes 21 LEE and non-LEE effectors (Iguchi et al., 2009). Other EPEC strains encode a greater number of T3SS effectors: 28 in EPEC B171 (Ogura et al., 2008), 40 in EPEC E22 and 24 in EPEC E110019 (Iguchi et al., 2009). EHEC O157 Sakai encodes 50 effectors, representing the most complex repertoire among A/E pathogens (Tobe et al., 2006). This shows that the $\mathrm{A} / \mathrm{E}$ pathogen class is much more heterogeneous than was previously thought, comprising strains expressing unique complements of T3SS effector proteins and as a result employing diverse infection strategies.

A novel family of T3SS effectors, known as the WxxxE proteins, was recently described (Alto et al., 2006), which include IpgB1 and IpgB2 from Shigella, SifA and SifB from Salmonella, and Map (Kenny \& Jepson, 2000), EspM (Arbeloa et al., 2008) and EspT (Bulgin et al., 2008) from EPEC and EHEC. Members of the WxxxE family are important virulence factors. For example, SifA is essential for intracellular Salmonella survival (Beuzon et al., 2000) and IpgB1 is essential for Shigella cell invasion (Ohya et al., 2005). Map, which is encoded on the LEE pathogenicity island and is absolutely conserved among EPEC and EHEC strains, plays a role in colonization in vivo (Mundy et al., 2004) and triggers transient filopodia by activating the Rho GTPase Cdc42 (Kenny et al., 2002; Berger et al., 2009). The different EspM variants induce formation of stress fibres by activating RhoA (Arbeloa et al., 2008), while EspT from the C. rodentium induces formation of extensive lamellipodia by activation of Rac-1 and Cdc42 (Bulgin et al., 2009). By sequence homology searches we recently identified homologues of espM and espT in EPEC strain E110019 (Bulgin et al., 2009), a clinical isolate from a diarrhoeal outbreak in

Table 1. Distribution of espM and espT among 151 non-O157 clinical EHEC strains (Spain)

The strains were isolated in Spain, except for strain FV10110 O111: H8, which was isolated in Germany. espM-espT negative strains were: ONT : HNT (2), ONT:H5 (1), ONT : H8 (1), ONT:H18 (1), ONT:H39 (1), O2: H27 (1), O8: H2 (1), O8: H19 (1), O15:H16 (1), O15:H28 (1), O18:ND (2), O22:H42 (1), O55:H- (1), O63:HND (2), O64:H21 (1), O76:ND (2), O76:H19 (2), O84:HNT (1), O84:HND (1), O91:H- (2), O98:H- (1), O104:HNT (4), O113:HND (2), O113:H21 (2), O117: HND (1), O136:HND (1), O141:HND (1), O146:H- (1), O146:H21 (4), O148:HND (2), O148: H8 (1), O165:H(1), O166:HND (1), O166: H28 (1), O168:H8 (1), O174:H21 (1), O183:H- (1).

\begin{tabular}{|c|c|c|c|c|}
\hline \multicolumn{2}{|c|}{ Serotype (no. of strains) } & \multirow[t]{2}{*}{ VT type } & \multirow[t]{2}{*}{ espM } & \multirow[t]{2}{*}{ espt } \\
\hline $\mathbf{O}$ & $\mathbf{H}$ & & & \\
\hline ONT (14) & HND (7), H- (6), H11 (1) & 1,2 & 4 & 0 \\
\hline O5 & HND (3) & 1,2 & 2 & 0 \\
\hline O14 & H- (1) & 1 & 1 & 0 \\
\hline O26 (37) & HND (17), H- (2), H8 (1), H11 (17) & 1 & 36 & 0 \\
\hline $\mathrm{O} 32$ & H6 (1) & 1 & 1 & 0 \\
\hline O69 & $\mathrm{H} 21$ (1) & 1 & 1 & 0 \\
\hline O80 & HND (1) & 1,2 & 1 & 0 \\
\hline O98 & $\mathrm{H} 21(1)$ & 1 & 1 & 0 \\
\hline O103 (6) & HND (1), H2 (5) & 1,2 & 6 & 0 \\
\hline O111 (10) & HND (5), H- (3), H8 (1)*, H10 (1) & 1,2 & 9 & 0 \\
\hline O118 (6) & HND (3), H- (1), H16 (2) & 1 & 6 & 0 \\
\hline O121 (2) & H19 (1), H40 (1) & 2 & 2 & 0 \\
\hline O145 (3) & HND (1), H- (2) & 1,2 & 3 & 0 \\
\hline $\mathrm{O} 146$ & HND (10) & 1,2 & 1 & 0 \\
\hline O156 & H25 (2) & 1 & 2 & 0 \\
\hline O139, O141 & HND (1) & 1,2 & 1 & 0 \\
\hline
\end{tabular}

VT, Verocytotoxin.

${ }^{*}$ Strain FV10110 O111: H8 was isolated in Germany. 
Finland in 1987 (Viljanen et al., 1990). $\mathrm{EspM}_{\mathrm{E} 110019}$ is $100 \%$ identical to the EspM of EHEC O157 Sakai, while $\mathrm{EspT}_{\mathrm{E} 110019}$ shares $79 \%$ sequence homology with the $C$. rodentium EspT, including the WxxxE motif. The aim of this study was to determine the prevalence of espM and espT among clinical EPEC and EHEC isolates.

\section{METHODS}

Bacterial strains. The bacterial strains used in this study included EPEC strains E2348/69 (Levine et al., 1978) and E110019 (Viljanen et al., 1990), EHEC O157:H7 strain Sakai (Hayashi et al., 2001), C. rodentium strain ICC169 (Barthold et al., 1976; Wiles et al., 2004), and 932 clinical EHEC and EPEC isolates.

Serotyping. The determination of $\mathrm{O}$ and $\mathrm{H}$ antigens was carried out using the method described by Guinée et al. (1981) employing all available $\mathrm{O}(\mathrm{O} 1-\mathrm{O} 185)$ and $\mathrm{H}(\mathrm{H} 1-\mathrm{H} 56)$ antisera. All antisera were obtained and absorbed with the corresponding cross-reacting antigens to remove the non-specific agglutinins. The $\mathrm{O}$ antisera were produced in the Laboratorio de Referencia de E. coli and the $\mathrm{H}$ antisera were obtained from the Statens Serum Institut, Copenhagen, Denmark.

Prevalence of espT and espM among clinical EPEC and EHEC strains. In order to screen for espM by PCR we used the eight espM sequences identified in EHEC O157 strain Sakai, EPEC strains B171 and E22, and C. rodentium to design common internal espM-1 (5'TCTTTCAGCTCTTTTGGTAT- $\left.3^{\prime}\right)$ and espM-2 (5' -CCAAAAGAAGCATTCCCCATTAT- $3^{\prime}$ ) forward and reverse primers (30 cycles of $94{ }^{\circ} \mathrm{C}$ for $45 \mathrm{~s}, 48{ }^{\circ} \mathrm{C}$ for $1 \mathrm{~min}$ and $72{ }^{\circ} \mathrm{C}$ for $1 \mathrm{~min}$ ). The identity of representative PCR amplicons was confirmed by DNA sequencing. A second round of PCR was employed to screen representative espM-1 and espM-2 PCR negative strains using primers espM-3 (5'TGATGAGGTCATGAAATGTTCAAT- $\left.3^{\prime}\right)$ and espM-4 (5'-ATGATTAATAGAACTTTG- $3^{\prime}$ ) (30 cycles of $94{ }^{\circ} \mathrm{C}$ for $45 \mathrm{~s}, 50{ }^{\circ} \mathrm{C}$ for $1 \mathrm{~min}$ and $72{ }^{\circ} \mathrm{C}$ for $1 \mathrm{~min}$ ).

We used the espT sequences from $C$. rodentium and E110019 to design internal espT-1 (5'-AATCTCATTCTCTTATC- $\left.3^{\prime}\right)$ and espT-2 (5'TCATGTGATGAGTGGATG-3') primers for PCR (30 cycles of $94{ }^{\circ} \mathrm{C}$ for $45 \mathrm{~s}, 55^{\circ} \mathrm{C}$ for $1 \mathrm{~min}$ and $72{ }^{\circ} \mathrm{C}$ for $\left.1 \mathrm{~min}\right)$.

A further three rounds of PCR were employed to screen representative espT-1 and espT-2 PCR-negative strains using additional common internal primers espT-3 (5'-ATAGATGGTTTCTTTTTAGG-3') and espT-4 (5'-CATCCAACGAGAAACCGCAAT- $\left.3^{\prime}\right)$, and primers espT-5 (5'-CCGgaattcATGCCGGGAACAATAAGCTCCAG-3') and espT-6 (5'-GGGAAGCTTTTAGGTTCTCTGAGCCTC-3') and espT-7 (5'TTGAATTCATGCATAGCATGCCAGGA-3') and espT-8 (5' -CCAATGCACTGCAGGGAGCATTAAACATATTTTAAATTTCTC-3'), which correspond to the $5^{\prime}$ and $3^{\prime}$ ends of the C. rodentium and E110019 espT homologue, respectively $\left(30\right.$ cycles of $94{ }^{\circ} \mathrm{C}$ for $45 \mathrm{~s}, 52{ }^{\circ} \mathrm{C}$ for $1 \mathrm{~min}$ and $72{ }^{\circ} \mathrm{C}$ for $1 \mathrm{~min}$ ).

EHEC O157: H7 Sakai, C. rodentium and EPEC E2348/69 were used as positive and negative controls.

Intimin, Tir and TccP typing of the espT-positive strains. Intimin and Tir typing was performed by PCR and sequencing as previously described (Blanco et al., 2006b; Garrido et al., 2006). The nucleotide sequence of the amplification products purified using a QIAquick DNA purification kit (Qiagen) was determined by the dideoxynucleotide triphosphate chain-termination method of Sanger, with a BigDye terminator v3.1 cycle sequencing kit and an ABI 3100 genetic analyzer (Applied Biosystems). The new eae sequences of the strains analysed were deposited in the European Bioinformatics Institute EMBL nucleotide sequence database. The presence of $t c c P 2$ was determined by PCR as described by Whale et al. (2007).

Table 2. Distribution of espM and espT among 132 tEPEC strains

espM-espT negative strains were: ONT:HND (1), ONT:H1, H12 (1), ONT:H8 (1), ONT:H25 (1), O1:H1, H12 (1), O55:H8 (1), O86:H8 (1), O88:H5 (2), O98:HND (1), O127:H40 (3), O131:H46 (2), O153:H8 (1), O157:H45 (1).

\begin{tabular}{|c|c|c|c|c|}
\hline \multicolumn{2}{|c|}{ Serotype (no. of strains) } & \multirow[t]{2}{*}{ Origin } & \multirow[t]{2}{*}{ espM } & \multirow[t]{2}{*}{$\operatorname{esp} T$} \\
\hline $\mathbf{O}$ & $\mathbf{H}$ & & & \\
\hline ONT (2) & H6 (1), H10 (1) & Bolivia & 2 & 0 \\
\hline O23 (2) & HND (1), H8 (1) & Spain & 2 & 0 \\
\hline O49 & $\mathrm{H} 10(5)$ & Spain, Bolivia & 5 & 0 \\
\hline O55 (22) & H- (8), H6 (6), H51 (8) & Uruguay, Bolivia, Brazil, UK & 19 & 0 \\
\hline O86 (6) & H- (2), H34 (4) & Bolivia, Brazil & 6 & 0 \\
\hline O88 (17) & H- (1), H6 (1), H25 (15) & Spain, Bolivia & 3 & 0 \\
\hline O103 (3) & H- (1), H7 (2) & Bolivia & 3 & 0 \\
\hline O109 & H- (2) & Spain, Chile & 1 & 0 \\
\hline O111 (20) & H- (12), H2 (7), H25 (1) & Spain, Bolivia, Brazil, Uruguay & 19 & 1 \\
\hline O118 (4) & HND (1), H- (1), H5 (2) & Spain, Germany & 4 & 0 \\
\hline O119 (17) & H- (2), H6 (15) & Bolivia, Brazil, Uruguay & 16 & 0 \\
\hline O125 & H- (1) & Burundi & 1 & 0 \\
\hline $\mathrm{O} 127$ & H6 (3) & Bolivia, Brazil & 1 & 0 \\
\hline O132 & H8 (1) & Bolivia & 1 & 0 \\
\hline O142 (6) & H6 (2), H34 (4) & Brazil, Spain & 4 & 0 \\
\hline O145 & $\mathrm{H} 45$ (3) & Brazil & 3 & 0 \\
\hline $\mathrm{O} 153$ & H11 (1) & Spain & 1 & 0 \\
\hline
\end{tabular}


Table 3. Distribution of espM and espT among 602 aEPEC strains

espM-espT negative strains were: ONT:H2 (2), ONT: H6 (4), ONT : H9 (1), ONT: H10 (2), ONT:H11, 21, 34 (1), ONT: H19 (2), ONT: H21, 39 (1), ONT:H34 (1), ONT:H40, 43 (2), ONT:H51 (1), O1:H2 (1), O1:H11 (1), O1:H46 (1), O1:H49 (1), O2ab:H45 (1), O2: NT (1), O2:H6 (1), O2:H16 (1), O2:H45 (1), O2:H49 (2), O3:H4 (1), O5:H6 (1), O5:H40 (1), O5:H49 (1), O6:H4 (1), O6:H16 (1), O9:HND (2), O11:H16 (2), O12:HND (1), O13:H11 (1), O15:H- (2), O15:H7 (1), O16:H- (1), O18:H7 (1), O18:H16 (1), O20:H6 (1), O21:HND (2), O21 : H15 (1), O23:HND (1), O24:H2 (1), O25:HND (2), O25:H1 (1), O26:H2 (1), O28: HND (1), O33: HNT (1), O33 : H6 (1), O33 : H34 (1), O34: H- (1), O41:H- (1), O49:H40 (1), O51:H41 (1), O55:H40 (1), O56:H6 (1), O63:HND (1), O64:H40 (1), O71:H1, H12 (2), O76: H19 (1), O84:HND (1), O84:H- (2), O85:H8 (1), O85:H49 (1), O86:HNT (1), O86:HND (1), O88, O168:HND (1), O98:H- (1), O98:H8 (1), O101:H33 (2), O103:H- (3), O103:H4 (1), O103:H19 (1), O103:H40 (1), O104:H- (2), O105:HND (1), O105:H4 (2), O108:HND (3), O110:HND (5), O111:H9 (1), O111:H38 (1), O112:H15 (1), O113:HND (4), O113:H- (1), O114:HND (1), O117:H11 (1), O117:H40 (2), O121:HND (1), O123:HND (1), O123:H19 (1), O123:H45 (1), O125:H6 (3), O127:HND (1), O127:H6 (1), O128:H40 (1), O129:HND (1), O129:H- (1), O132:HND (3), O132:H5 (3), O137:HND (3), O137:H6 (2), O139:HND (4), O139:H2 (1), O141:HND (10), O145:H2 (1), O146:H28 (1), O148:H8 (1), O153:H11 (1), O153:H31 (1), O153:H40 (1), O156:H4 (1), O156:H8 (3), O156:H33 (1), O157:H16 (2), O159: HND (1), O164:H- (1), O167:H27 (1), O168:H- (1), O171:H19 (1), O173:H- (1), O178:H6 (1), O180:HND (1), O180:H2 (1), R:H28 (1).

\begin{tabular}{|c|c|c|c|c|}
\hline \multicolumn{2}{|c|}{ Serotype (no. of strains) } & \multirow[t]{2}{*}{ Origin } & \multirow[t]{2}{*}{ espM } & \multirow[t]{2}{*}{ esp T } \\
\hline $\mathbf{O}$ & $\mathbf{H}$ & & & \\
\hline O1 (3) & H7 (1), H40 (1), H45 (1) & Brazil, Spain & 3 & 0 \\
\hline O2 (11) & ND (3), H40 (8) & Spain & 3 & 2 \\
\hline O6 (2) & ND (1), H19 (1) & Spain & 2 & 0 \\
\hline O8 (5) & HND (3), H11 (1), H19 (1) & Spain & 3 & 0 \\
\hline O10 (5) & $\mathrm{HN}(3), \mathrm{H}-(2)$ & Spain & 4 & 0 \\
\hline $\mathrm{O} 11$ & HND (4) & Spain & 4 & 0 \\
\hline $\mathrm{O} 14$ & H5 (1) & Brazil & 1 & 0 \\
\hline $\mathrm{O} 25$ & $\mathrm{H} 2(1)$ & Spain & 1 & 0 \\
\hline O26 (30) & $\mathrm{ND}(20), \mathrm{H}-(6), \mathrm{H} 11$ (4) & Spain, Brazil & 23 & 0 \\
\hline $\mathrm{O} 28$ & $\mathrm{H} 28$ & Bolivia & 1 & 0 \\
\hline $\mathrm{O} 33$ & HND (3) & Spain & 1 & 0 \\
\hline O49 (12) & HND (6), H- (3), H2 (1), H10 (2) & Spain, Brazil & 6 & 1 \\
\hline O51 (16) & HND (5), H- (2), H1 (1), H40 (6), H49 (2) & Spain, Brazil & 7 & 0 \\
\hline O52 & $\mathrm{H} 10(1)$ & Spain & 1 & 0 \\
\hline O57 & H7 (3) & Spain & 3 & 0 \\
\hline O55 (16) & HND (4), H- (1), H6 (1), H7 (9), H51 (1) & Spain, Brazil, Bolivia & 15 & 0 \\
\hline O56 & $\mathrm{H}-(1)$ & Spain & 1 & 0 \\
\hline O63 (6) & H6 (5), H33 (1) & Spain, Brazil & 2 & 0 \\
\hline O103 (12) & HND (11), H2 (1) & Spain & 4 & 0 \\
\hline O104 (4) & HND (1), H2 (2), H12 (1) & Spain, Brazil & 2 & 2 \\
\hline O109 & H9 (1) & Brazil & 1 & 1 \\
\hline O111 (2) & HND (1), H- (1) & Spain & 2 & 0 \\
\hline O113 & H6 (4) & Spain & 1 & 0 \\
\hline O115 (4) & HND (1), H8 (3) & Spain & 3 & 0 \\
\hline $\mathrm{O} 117$ & HND (4) & Spain & 2 & 0 \\
\hline
\end{tabular}


Table 3. cont.

\begin{tabular}{|c|c|c|c|c|}
\hline \multicolumn{2}{|c|}{ Serotype (no. of strains) } & \multirow[t]{2}{*}{ Origin } & \multirow[t]{2}{*}{ espM } & \multirow[t]{2}{*}{ espt } \\
\hline $\mathbf{O}$ & & & & \\
\hline O119 & HND (2) & Spain & 2 & 0 \\
\hline O120 & HND (2) & Spain & 1 & 0 \\
\hline $\mathrm{O} 123$ & H- (2) & Brazil & 2 & 2 \\
\hline $\mathrm{O} 125$ & $\mathrm{H} 28(1)$ & Spain & 1 & 0 \\
\hline $\mathrm{O} 127$ & $\mathrm{H} 40$ (5) & Spain, Bolivia & 1 & 0 \\
\hline O128 (4) & HND (1), H- (1), H2 (1), H27 (1) & Spain & 4 & 0 \\
\hline $\mathrm{O} 132$ & H34 (3) & Spain & 3 & 0 \\
\hline O139 & H19 (1) & Spain & 1 & 0 \\
\hline O145 (33) & & Spain, Germany & 25 & 0 \\
\hline O146 & HND (1) & Spain & 1 & 0 \\
\hline $\mathrm{O} 153$ & HND (15) & Spain & 2 & 0 \\
\hline O154 & H9 (1) & Brazil & 1 & 1 \\
\hline O156 (8) & HND (6), H- (2) & Spain & 4 & 0 \\
\hline O157 (5) & ND (2), H7 (3) & Spain & 4 & 0 \\
\hline O162 (4) & H- (2), H21 (1), H33 (1) & Spain, Brazil & 3 & 0 \\
\hline O166 & HND (1) & Spain & 1 & 0 \\
\hline O167 (4) & ND (2), H9 (1), H11 (1) & Spain & 3 & 0 \\
\hline O177 & H11 (1) & Spain & 1 & 0 \\
\hline $\mathrm{O} 178$ & H7 (1) & Spain & 1 & 0 \\
\hline $\mathrm{O} 179$ & H31 (1) & Spain & 1 & 0 \\
\hline O115, O152 (15) & HND (13), H8 (1), H10 (1) & Spain & 10 & 0 \\
\hline $\mathrm{R}(2)$ & H11, 21 (1), H28 (1) & Brazil & 1 & 0 \\
\hline
\end{tabular}

\section{RESULTS AND DISCUSSION}

\section{Screening 0157 and non-0157 EHEC strains for the presence of espM and espT}

We determined the prevalence of espM and esp T among 45 non-sorbitol fermenting (non-SF) EHEC O157:H7 (expressing VT1 and VT2), isolated in Spain, Canada and Bolivia, and two SF EHEC O157:H- (expressing VT2), isolated in Germany. espM was found in 43 of the non-SF O157 isolates $(96 \%)$ and in the 2 SF isolates. We then screened 151 non-O157 EHEC strains. espM was found in 60 of the $62(97 \%)$ non-O157 EHEC strains belonging to

Table 4. Characterization of the espT-positive strains

\begin{tabular}{|c|c|c|c|c|c|c|c|}
\hline $\begin{array}{l}\text { Serotype } \\
\text { (no. } \\
\text { of strains) }\end{array}$ & Origin & Pathotype & espM & Intimin & Tir & Tccp2 & $\begin{array}{c}\text { GenBank } \\
\text { accession no. }\end{array}$ \\
\hline \multicolumn{8}{|l|}{ Group 1} \\
\hline O111: H9 (1) & Finland & aEPEC & + & $\zeta 2$ & $\alpha 1$ & + & \\
\hline ONT:H- (1) & Brazil & aEPEC & + & $\varepsilon 2$ & $\alpha 1$ & + & FM992854 \\
\hline O49:H- (1) & Brazil & aEPEC & + & $\zeta 2$ & $\alpha 1$ & + & FM992855 \\
\hline O85:H- (1) & Brazil & aEPEC & - & $\iota 1$ & $\alpha 1$ & + & FM992856 \\
\hline O109: H9 (1) & Brazil & aEPEC & + & $\varepsilon 2$ & $\alpha 1$ & + & FM992857 \\
\hline O111:H- (1) & Spain & tEPEC & + & $\zeta 2$ & $\alpha 1$ & + & FM992858 \\
\hline O123:H- (2) & Brazil & aEPEC & + & $\varepsilon 2$ & $\alpha 1$ & + & FM992859 \\
\hline O154:H9 (1) & Brazil & aEPEC & + & $\zeta 2$ & $\alpha 1$ & + & FM992860 \\
\hline \multicolumn{8}{|l|}{ Group 2} \\
\hline $\mathrm{O} 2: \mathrm{H} 49$ (1) & Spain & aEPEC & - & $\theta 1$ & $\theta 1$ & + & FM992862 \\
\hline $\mathrm{O} 2: \mathrm{H} 49$ (1) & Spain & aEPEC & - & $t 1$ & $\alpha 1$ & - & FM992861 \\
\hline \multicolumn{8}{|l|}{ Group 3} \\
\hline ONT: H7 (1) & Brazil & aEPEC & + & $\beta 1$ & $\beta 1$ & - & FM992863 \\
\hline $\mathrm{O} 104: \mathrm{H} 2(1)$ & Spain & aEPEC & - & $\beta 1$ & $\beta 1$ & + & FM992864 \\
\hline $\mathrm{O} 104: \mathrm{H} 2(1)$ & Brazil & aEPEC & - & $\beta 1$ & $\beta 1$ & + & FM992865 \\
\hline
\end{tabular}


serogroups O26, O103, O111, O118 and O145 (Table 1). In contrast espM was found in only 17 of 89 (19\%) strains belonging to the other non-O157 serogroups (Table 1). All the $\mathrm{O} 157$ and non-O157 strains were espT gene negative.

In order to confirm the absence of espM and espT from the PCR gene-negative strains, we screened $50 \mathrm{O} 157$ and nonO157 EHEC strains with a second set of conserved espM primers (espM-3 and espM-4) and three sets of espT primers (espT-3 and espT-4, espT-5 and espT-6, and espT-7 and espT-8). All the isolates remained espM and esp $T$ gene negative in these tests.

\section{Screening tEPEC and aEPEC isolates for the presence of espM and espT}

We screened a total of 132 tEPEC strains, isolated in Brazil, Bolivia, Burundi, Spain, Chile, Germany, the UK and Uruguay, and 602 aEPEC strains, isolated in Brazil, Bolivia, Chile and Spain, for the presence of espM and espT. espM was found in 91 tEPEC isolates (69\%) belonging to 16 different serogroups (the $\mathrm{O}$ serogroup of 6 strains was nontypable - ONT) (Table 2). espM was found in 258 aEPEC isolates $(43 \%)$ belonging to 59 different serogroups [the $\mathrm{O}$ serogroup of 109 strains was ONT and of 2 isolates was O rough (R)] (Table 3). Of the 109 ONT aEPEC, espM was found in 45 isolates (41\%). Among the aEPEC that shared a serogroup with the major EHEC strains, espM was found in 23 of $31(74 \%)$ O26, 4 of 12 (33\%) O103, 2 of $4(50 \%)$ O111, 25 of $33(76 \%)$ O145 and 4 of $7(57 \%)$ O157 isolates; in total 58 of 87 (67\%). Interestingly, espM was found in $94 \%$ ( 15 of 16) of the O55 strains, regardless of serotype. espT was found in only $1(0.8 \%)$ tEPEC strain $(\mathrm{O} 111: \mathrm{H}-)$ isolated in Spain and in 12 aEPEC strains $(2 \%)$ (Table 3).

In order to confirm the absence of espM and esp $T$ from the PCR gene-negative EPEC strains, we screened 50 tEPEC and 100 aEPEC strains with espM primers 3 and 4, and $\operatorname{esp} T$ primers 3 and 4,5 and 6, and 7 and 8. All the isolates remained espM and espT gene negative in these tests.

\section{Further characterization of the espT-positive strains}

Considering that espT was found in only 13 of the total 932 isolates tested, we sequenced their amplicons, and characterized their virulence genes implicated in colonization (e.g. intimin type) and pedestal formation (e.g. Tir type and TccP2) as described previously (Garmendia et al., 2005b); strain E110019 was used as a reference strain. Sequencing of esp T revealed a high level of sequence conservation (Table 4). In the eight strains EspT was identical to that of E110019, defined as group 1 EspT. In two strains we detected a single amino acid difference (group 2) and in three other strains we found 6 amino acids that differed from the EspT of E110019 (group 3) (Fig. 1). All the espT-positive strains encoded a Tir that can undergo tyrosine phosphorylation and thus trigger strong actin polymerization in vitro via the Nck-N-WASP pathway (Kenny, 1999; Gruenheid et al., 2001). All the strains but two encoded TccP2, which can also activate the N-WASP actin-signalling pathway (Whale et al., 2007). Eight of the espT-positive strains (as well as E110019) also encoded EspM.

Intimin typing was performed by sequencing the variable $3^{\prime}$ end of the eae gene from the 14 espT-positive strains (including E110019) (Table 4) (Blanco et al., 2006b). This revealed known intimin types in 10 strains: $\beta 1$ (3 strains), $\varepsilon 2$ (4 strains), $\theta 1$ ( 1 strain) and $\iota 1$ (2 strains). Importantly, we identified a new intimin variant, $\zeta 2$, in 4 of the espT gene-positive strains (Table 4). We determined the complete nucleotide sequence of two of the new eae- $\zeta 2$ variant genes (accession numbers FM872419 and FM872420 for E110019 and T2381-8, respectively). Using CLUSTAL W software for optimal sequence alignment with the known 27 eae alleles, we found 98, 92 and $91 \%$ sequence identity with the eae- $\zeta 1$ (AJ271407), eae- $\alpha 1$ (M58154) and eae- $\alpha 2$ (AF530555) genes, respectively.

\section{Conclusions}

Our results show that espM is found in approximately $96 \%$ of the strains belonging to the major EHEC serogroups: O26, O103, O111, O118, O145 and O157, and in a
EspT 1/E110019 TVNSCGEGES ITKAPYSSGQ KPVIDGFFLG ARRISESYPR LESELIQCIN ESPT 2 TVNSCGFGFS ITKAPYSSGQ KPVIDGFFLG ARRISFSYPR LESELIQCIN ESPT 3 TVNSCGFGFS ITKAPYSSGQ KPFIDGFFLG ARKISFSYPR LESELIQCIN 58

ESPT 1/E110019 LKNEGKKNEW MKEASICEVS RDVNKLLDME AKNNQTNIPK GVRERVFQLA EspT 2 LKNEGKKNEW MKEESICFVS RDVNKLLDME AKNNQTNIPK GVRERVFQLA EsPT 3 LKNEGKKNEW MKEEGICFVS RDVNKLLDMF AKNNQTNIPE GVRERVFQLA 108

EspT 1/E110019 SFYCGFSLDA RCAQASTHHM ILNSQYFQKK MDTLLTSVDI NVRNQCVRTA ESPT 2 SFYCGESLDA RCAQTSTHHM ILNSQYFQKK MDTLLTSVDI NVRNQCVRTA ESPT 3 SEYCGESLDA RCAQTSTHHM ILNSQYFQKK MDTLLTSVDI NVRNQCVRTA

$\begin{array}{lll} & 158 & 190 \\ \text { EspT } 1 / \text { E110019 LSSLADTFFE NNVNNIDMNK LRDRVHNTIV OEV }\end{array}$ ESPT 2 ISSLADTEFE NNVNNIDMNK LRDRVHNTIV OEV ESPT 3 LSSLADTFEE NNVNNIDMNK FRDRVHNTIV QEV
Fig. 1. Multiple sequence alignment of representative EspT sequences. The conserved motif $\mathrm{W} x x \mathrm{E}$ is boxed. When compared with $\mathrm{EspT}_{\mathrm{E} 110019}, 8$ of the $13 \mathrm{EspT}$ showed $100 \%$ sequence identity (ONT: $\mathrm{H}-, \mathrm{O} 49: \mathrm{H}-$, $\mathrm{O} 85: \mathrm{H}-, \quad \mathrm{O} 109: \mathrm{H} 9, \quad \mathrm{O} 111: \mathrm{H}-, \quad \mathrm{O} 123: \mathrm{H}-$ (2), $\mathrm{O} 154: \mathrm{H} 9)$ as represented by sequence EspT 1. Two strains belonging to serotype $\mathrm{O} 2$ : $\mathrm{H} 49$ had 1 amino acid difference, indicated by dark grey (sequence EspT 2), while three strains $\mathrm{O} 104: \mathrm{H} 2$ (2), ONT:H (7) differed in 6 amino acids, indicated by dark grey and light grey (sequence EspT 3). 
significantly higher proportion than in other non-O157 EHEC strains $(P<0.05)$. Similarly, espM was also more commonly found in EPEC serogroups O26, O55, O145 and O157 than in other aEPEC. Among the tEPEC strains espM was detected in approximately $69 \%$ of the tested isolates. These results suggest that espM is more commonly found in EPEC and EHEC serogroups that are linked to severe human infections. In contrast, espT was found only infrequently and only among EPEC strains (1 tEPEC and 12 aEPEC isolates). espT was first found in C. rodentium and later in silico in EPEC E110019, which is of particular interest as it was responsible for a particularly severe diarrhoeal outbreak in Finland in 1987 that affected 650 individuals, including adults, in a school complex and an additional 137 associated household members (Viljanen et al., 1990). Comparing the protein sequences of EspT to that of E110019 showed a high level of conservation, with only three strains encoding EspT that differed in 6 amino acids from the EspT of E110019. At present, it is not clear why espT is so rare and what impact EspM and EspT have on EPEC and EHEC infection.

\section{ACKNOWLEDGEMENTS}

We thank Jim Kaper for the E11001119 strain. A. Mora acknowledges the Ramón y Cajal programme from the Spanish Ministry of Education and Science. Work in the laboratory of Jorge Blanco was supported by grants from the Spanish Ministry of Health and Consumer Affairs [Fondo de Investigación Sanitaria, Spanish Network for the Research in Infectious Diseases (REIPI) RD06/ 0008-1018], Spanish Ministry of Education and Science (AGL-200802129) and the Autonomous Government of Galicia (Xunta de Galicia, PGIDIT065TAL26101P, 07MRU036261PR). Work in the laboratory of T.A.T. G. was supported by Fundação de Amparo à Pesquisa do Estado de São Paulo (FAPESP) grant 08/53812-4, and Programa de Apoio a Núcleos de Excelência - PRONEX MCT/CNPq/ FAPERJ. F. C. M. received a fellowship from FAPESP. Work in the laboratory of Gad Frankel was supported by the MRC and the Wellcome Trust.

\section{REFERENCES}

Alto, N. M., Shao, F., Lazar, C. S., Brost, R. L., Chua, G., Mattoo, S., McMahon, S. A., Ghosh, P., Hughes, T. R. \& other authors (2006). Identification of a bacterial type III effector family with $G$ protein mimicry functions. Cell 124, 133-145.

Arbeloa, A., Bulgin, R. R., MacKenzie, G., Shaw, R. K., Pallen, M. J., Crepin, V. F., Berger, C. N. \& Frankel, G. (2008). Subversion of actin dynamics by EspM effectors of attaching and effacing bacterial pathogens. Cell Microbiol 10, 1429-1441.

Barthold, S. W., Coleman, G. L., Bhatt, P. N., Osbaldiston, G. W. \& Jonas, A. M. (1976). The etiology of transmissible murine colonic hyperplasia. Lab Anim Sci 26, 889-894.

Berger, C. N., Crepin, V. F., Jepson, M. A., Arbeloa, A. \& Frankel, G. (2009). The mechanisms used by enteropathogenic Escherichia coli to control filopodia dynamics. Cell Microbiol 11, 309-322.

Beuzon, C. R., Meresse, S., Unsworth, K. E., Ruiz-Albert, J., Garvis, S., Waterman, S. R., Ryder, T. A., Boucrot, E. \& Holden, D. W. (2000). Salmonella maintains the integrity of its intracellular vacuole through the action of SifA. EMBO J 19, 3235-3249.
Blanco, M., Blanco, J. E., Dahbi, G., Alonso, M. P., Mora, A., Coira, M. A., Madrid, C., Juarez, A., Bernardez, M. I. \& other authors (2006a). Identification of two new intimin types in atypical enteropathogenic Escherichia coli. Int Microbiol 9, 103-110.

Blanco, M., Blanco, J. E., Dahbi, G., Mora, A., Alonso, M. P., Varela, G., Gadea, M. P., Schelotto, F., Gonzalez, E. A. \& Blanco, J. (2006b). Typing of intimin (eae) genes from enteropathogenic Escherichia coli (EPEC) isolated from children with diarrhoea in Montevideo, Uruguay: identification of two novel intimin variants $(m u B$ and xiR/beta2B). J Med Microbiol 55, 1165-1174.

Bulgin, R. R., Arbeloa, A., Chung, J. C. \& Frankel, G. (2009). EspT triggers formation of lamellipodia and membrane ruffles through activation of Rac-1 and Cdc42. Cell Microbiol 11, 217-229.

Chen, H. D. \& Frankel, G. (2005). Enteropathogenic Escherichia coli: unravelling pathogenesis. FEMS Microbiol Rev 29, 83-98.

Frankel, G. \& Phillips, A. D. (2008). Attaching effacing Escherichia coli and paradigms of Tir-triggered actin polymerization: getting off the pedestal. Cell Microbiol 10, 549-556.

Garmendia, J., Frankel, G. \& Crepin, V. F. (2005a). Enteropathogenic and enterohemorrhagic Escherichia coli infections: translocation, translocation, translocation. Infect Immun 73, 2573-2585.

Garmendia, J., Ren, Z., Tennant, S., Midolli Viera, M. A., Chong, Y., Whale, A., Azzopardi, K., Dahan, S., Sircili, M. P. \& other authors (2005b). Distribution of $t c c P$ in clinical enterohemorrhagic and enteropathogenic Escherichia coli isolates. J Clin Microbiol 43, 57155720.

Garrido, P., Blanco, M., Moreno-Paz, M., Briones, C., Dahbi, G., Blanco, J. \& Parro, V. (2006). STEC-EPEC oligonucleotide microarray: a new tool for typing genetic variants of the LEE pathogenicity island of human and animal Shiga toxin-producing Escherichia coli (STEC) and enteropathogenic E. coli (EPEC) strains. Clin Chem 52, 192-201.

Gruenheid, S., DeVinney, R., Bladt, F., Goosney, D., Gelkop, S., Gish, G. D., Pawson, T. \& Finlay, B. B. (2001). Enteropathogenic E. coli Tir binds Nck to initiate actin pedestal formation in host cells. Nat Cell Biol 3, 856-859.

Guinée, P. A. M., Jansen, W. H., Wadström, T. \& Sellwood, R. (1981). Escherichia coli associated with neonatal diarrhoea in piglets and calves. Curr Top Vet Anim Sci 13, 126-162.

Hayashi, T., Makino, K., Ohnishi, M., Kurokawa, K., Ishii, K., Yokoyama, K., Han, C. G., Ohtsubo, E., Nakayama, K. \& other authors (2001). Complete genome sequence of enterohemorrhagic Escherichia coli $\mathrm{O} 157: \mathrm{H} 7$ and genomic comparison with a laboratory strain K-12. DNA Res 8, 11-22.

Iguchi, A., Thomson, N. R., Ogura, Y., Saunders, D., Ooka, T., Henderson, I. R., Harris, D., Asadulghani, M., Kurokawa, K. \& other authors (2009). Complete genome sequence and comparative genome analysis of enteropathogenic Escherichia coli O127 : H6 strain E2348/69. J Bacteriol 191, 347-354.

Jarvis, K. G., Girón, J. A., Jerse, A. E., McDaniel, T. K., Donnenberg, M. S. \& Kaper, J. B. (1995). Enteropathogenic Escherichia coli contains a putative type III secretion system necessary for the export of proteins involved in attaching-effacing lesions formation. Proc Natl Acad Sci U S A 92, 7996-8000.

Jerse, A. E., Yu, J., Tall, B. D. \& Kaper, J. B. (1990). A genetic locus of enteropathogenic Escherichia coli necessary for the production of attaching and effacing lesions on tissue culture cells. Proc Natl Acad Sci U S A 87, 7839-7843.

Kaper, J. B. (1996). Defining EPEC. Rev Microbiol Sao Paulo 27, 130133.

Kenny, B. (1999). Phosphorylation of tyrosine 474 of the enteropathogenic Escherichia coli (EPEC) Tir receptor molecule is essential 
for actin nucleating activity and is preceded by additional host modifications. Mol Microbiol 31, 1229-1241.

Kenny, B. \& Jepson, M. (2000). Targeting of an enteropathogenic Escherichia coli (EPEC) effector protein to host mitochondria. Cell Microbiol 2, 579-590.

Kenny, B., DeVinney, R., Stein, M., Reinscheid, D. J., Frey, E. A. \& Finlay, B. B. (1997). Enteropathogenic Escherichia coli (EPEC) transfers its receptor for intimate adherence into mammalian cells. Cell 91, 511-520.

Kenny, B., Ellis, S., Leard, A. D., Warawa, J., Mellor, H. \& Jepson, M. A. (2002). Co-ordinate regulation of distinct host cell signalling pathways by multifunctional enteropathogenic Escherichia coli effector molecules. Mol Microbiol 44, 1095-1107.

Knutton, S., Lloyd, D. R. \& McNeish, A. S. (1987). Adhesion of enteropathogenic Escherichia coli to human intestinal enterocytes and cultured human intestinal mucosa. Infect Immun 55, 69-77.

Levine, M. M., Bergquist, E. J., Nalin, D. R., Waterman, D. H., Hornick, R. B., Young, C. R. \& Sotman, S. (1978). Escherichia coli strains that cause diarrhoea but do not produce heat-labile or heat-stable enterotoxins and are non-invasive. Lancet 1, 1119-1122.

Mundy, R., Petrovska, L., Smollett, K., Simpson, N., Wilson, R. K., Yu, J., $\mathrm{Tu}, \mathrm{X}$., Rosenshine, I., Clare, S. \& other authors (2004). Identification of a novel Citrobacter rodentium type III secreted protein, EspI, and roles of this and other secreted proteins in infection. Infect Immun 72, 2288-2302.

Mundy, R., MacDonald, T. T., Dougan, G., Frankel, G. \& Wiles, S. (2005). Citrobacter rodentium of mice and man. Cell Microbiol 7, 1697-1706.

Nataro, J. P. \& Kaper, J. B. (1998). Diarrheagenic Escherichia coli. Clin Microbiol Rev 11, 142-201.
Ogura, Y., Abe, H., Katsura, K., Kurokawa, K., Asadulghani, M., Iguchi, A., Ooka, T., Nakayama, K., Yamashita, A. \& other authors (2008). Systematic identification and sequence analysis of the genomic islands of the enteropathogenic Escherichia coli strain B171-8 by the combined use of whole-genome PCR scanning and fosmid mapping. J Bacteriol 190, 6948-6960.

Ohya, K., Handa, Y., Ogawa, M., Suzuki, M. \& Sasakawa, C. (2005). IpgB1 is a novel Shigella effector protein involved in bacterial invasion of host cells. Its activity to promote membrane ruffling via Racl and Cdc42 activation. J Biol Chem 280, 24022-24034.

Tarr, P. I. (1995). Escherichia coli O157: H7: clinical, diagnostic, and epidemiological aspects of human infection. Clin Infect Dis 20, $1-8$.

Tobe, T., Beatson, S. A., Taniguchi, H., Abe, H., Bailey, C. M., Fivian, A., Younis, R., Matthews, S., Marches, O. \& other authors (2006). An extensive repertoire of type III secretion effectors in Escherichia coli $\mathrm{O} 157$ and the role of lambdoid phages in their dissemination. Proc Natl Acad Sci U S A 103, 14941-14946.

Viljanen, M. K., Peltola, T., Junnila, S. Y., Olkkonen, L., Jarvinen, H., Kuistila, M. \& Huovinen, P. (1990). Outbreak of diarrhoea due to Escherichia coli $\mathrm{O} 111$ : B4 in schoolchildren and adults: association of $\mathrm{Vi}$ antigen-like reactivity. Lancet 336, 831-834.

Whale, A. D., Hernandes, R. T., Ooka, T., Beutin, L., Schuller, S., Garmendia, J., Crowther, L., Vieira, M. A., Ogura, Y. \& other authors (2007). TccP2-mediated subversion of actin dynamics by EPEC $2-\mathrm{a}$ distinct evolutionary lineage of enteropathogenic Escherichia coli. Microbiology 153, 1743-1755.

Wiles, S., Clare, S., Harker, J., Huett, A., Young, D., Dougan, G. \& Frankel, G. (2004). Organ specificity, colonization and clearance dynamics in vivo following oral challenges with the murine pathogen Citrobacter rodentium. Cell Microbiol 6, 963-972. 